\title{
Promotion of chloroplast proliferation upon enhanced post-mitotic cell expansion in leaves
}

\author{
Kensuke Kawade ${ }^{1,4^{*}}$, Gorou Horiguchi ${ }^{2,3}$, Naoko Ishikawa ${ }^{1}$, Masami Yokota Hirai ${ }^{4}$ and Hirokazu Tsukaya ${ }^{1}$
}

\begin{abstract}
Background: Leaves are determinate organs; hence, precise control of cell proliferation and post-mitotic cell expansion is essential for their growth. A defect in cell proliferation often triggers enhanced post-mitotic cell expansion in leaves. This phenomenon is referred to as 'compensation'. Several lines of evidence from studies on compensation have shown that cell proliferation and post-mitotic cell expansion are coordinately regulated during leaf development. Therefore, compensation has attracted much attention to the mechanisms for leaf growth. However, our understanding of compensation at the subcellular level remains limited because studies of compensation have focused mainly on cellular-level phenotypes. Proper leaf growth requires quantitative control of subcellular components in association with cellular-level changes. To gain insight into the subcellular aspect of compensation, we investigated the well-known relationship between cell area and chloroplast number per cell in compensation-exhibiting lines, and asked whether chloroplast proliferation is modulated in response to the induction of compensation.
\end{abstract}

Results: We first established a convenient and reliable method for observation of chloroplasts in situ. Using this method, we analyzed Arabidopsis thaliana mutants fugu5 and angustifolia3 (an3), and a transgenic line KIP-RELATED PROTEIN2 overexpressor (KRP2 OE), which are known to exhibit typical features of compensation. We here showed that chloroplast number per cell increased in the subepidermal palisade tissue of these lines. We analyzed tetraploidized wild type, fugu5, an3 and KRP2 OE, and found that cell area itself, but not nuclear ploidy, is a key parameter that determines the activity of chloroplast proliferation. In particular, in the case of an3, we uncovered that promotion of chloroplast proliferation depends on the enhanced post-mitotic cell expansion. The expression levels of chloroplast proliferation-related genes are similar to or lower than that in the wild type during this process.

Conclusions: This study demonstrates that chloroplast proliferation is promoted in compensation-exhibiting lines. This promotion of chloroplast proliferation takes place in response to cell-area increase in post-mitotic phase in an3. The expression of chloroplast proliferation-related genes were not promoted in compensation-exhibiting lines including an3, arguing that an as-yet-unknown mechanism is responsible for modulation of chloroplast proliferation in these lines.

Keywords: Cell area, Chloroplast number per cell, Compensation, Leaf growth, Nuclear ploidy

\section{Background}

Leaf growth is driven by spatiotemporal control of cell proliferation and post-mitotic cell expansion. In the early developmental stage, cell proliferation actively occurs throughout leaf primordia. The proliferating region is maintained within a constant distance from the leaf

\footnotetext{
* Correspondence: kensuke.kawade@riken.jp

'Department of Biological Sciences, Graduate School of Science, University of

Tokyo, 7-3-1 Hongo, Bunkyo-ku, Tokyo 113-0033, Japan

${ }^{4}$ RIKEN Center for Sustainable Resource Science, 1-7-22 Suehiro-cho,

Tsurumi-ku, Yokohama, Kanagawa 230-0045, Japan

Full list of author information is available at the end of the article
}

base, then abruptly disappeared from distal to proximal regions of the leaf blade [1-5]. After arrest of mitotic cycling, cells show post-mitotic expansion with an intense increase in vacuolar volume. During leaf development, a defect in cell proliferation often triggers enhanced postmitotic cell expansion. This phenomenon is termed 'compensation' [6-8] and is widely observed in seed plants including Arabidopsis thaliana (hereafter Arabidopsis) and Oryza sativa [9-11]. Interestingly, our recent study of compensation revealed that the two driving forces of leaf growth - proliferation and post-mitotic expansion of cells- are coordinately regulated during development

\section{Biomed Central}

(c) 2013 Kawade et al.; licensee BioMed Central Ltd. This is an Open Access article distributed under the terms of the Creative Commons Attribution License (http://creativecommons.org/licenses/by/2.0), which permits unrestricted use, distribution, and reproduction in any medium, provided the original work is properly cited. 
[12]. Compensation is therefore considered to be a key phenomenon for understanding the control of leaf growth.

Enhanced post-mitotic cell expansion could be detected by observing leaf cells from a paradermal view and measuring their area. Kinetics of the cell-area changes indicated that increase in cell area takes place in three distinct manner in compensation-exhibiting lines represented by angustifolia3 (an3) (enhanced rate of post-mitotic cell expansion), fugu5 (prolonged postmitotic cell expansion) and a cyclin dependent kinase inhibitor gene KIP-RELATED PROTEIN2 overexpressor (KRP2 OE) (increase in cell area in both mitotic and post-mitotic phases) [10,13]. The an3 is well characterized among compensation-exhibiting lines. The AN3 gene, also known as GRF-INTERACTING FACTOR1, encodes a transcriptional co-activator for leaf cell proliferation in Arabidopsis [14-16]. In the an3 leaves, cell number is decreased by more than $70 \%$ but cell area is increased by $50 \%$ when compared with the WT [10,15-17]. For induction of enhanced post-mitotic cell expansion, a decrease in cell proliferation below a threshold is required [18]. This fact suggests that enhanced post-mitotic cell expansion in an3 is not a simple result of a defect in cell proliferation, but a result of an active motion for leaf growth in response to a defect in cell proliferation. This idea is supported by our recent analysis of chimeric leaves for $A N 3$ expression: an3 mutant cells are considered to actively produce and transmit an inter-cellular signal for enhanced post-mitotic cell expansion [12]. These studies have deepened our understanding of the mechanism of compensation, and hence leaf growth, at the cellular level.

On the other hand, subcellular aspects in compensationexhibiting lines including an3 have received less attention. Quantitative control of subcellular components is required for the proper functioning of leaf cells. Anatomical studies have revealed that the number of chloroplasts per cell is correlated with cell area [19-21]. In this study, we investigated the number of chloroplasts per cell in compensationexhibiting lines to address whether subcellular aspect is affected in response to the induction of compensation.

Chloroplasts are derived from proplastids in meristematic cells, and multiply by division during leaf development. Two paralogous nucleus-encoded genes PLASTID DIVISION1 (PDV1) and PDV2 are involved in the chloroplast proliferation [22-24]. The expression for PDV1 and PDV2 in Arabidopsis occurs in the shoot apical meristem and in young leaf primordia, and then decreases in parallel with cessation of chloroplast proliferation [23,24]. Importantly, overexpression of $P D V 1$ and/or $P D V 2$ increases the number of chloroplasts, while a loss-of-function mutation in PDV1 and/or PDV2 has the opposite effect [22-24]. Other components involved in chloroplast proliferation have been also identified such as self-assembling cytoskeletal GTPase genes Filamentous temperature sensitive Z1 (FtsZ1) and FtsZ2 [25], a gene encoding J-domain containing protein ACCUMULATION AND REPLICATION OF CHLOROPLASTS 6 (ARC6) [26], Min systemrelated genes $[\mathrm{MinC}, \mathrm{MinD}, \mathrm{MinE}$ and MULTIPLE CHLOROPLAST DIVISION SITE 1 (MCD1)] [27,28]. Although involvement of these genes into chloroplast proliferation is apparent, it is known that overexpression or knockdown/knockout of them does not promote chloroplast proliferation [25-31]. Therefore, the extent of chloroplast proliferation depends primarily on the expression levels of $P D V \mathrm{~s}$. It is worth investigating the expression level of $P D V \mathrm{~s}$ in compensation-exhibiting lines to determine whether chloroplast proliferation is modulated in response to the induction of compensation.

We here established a convenient method for counting chloroplasts in subepidermal palisade cells in situ. By use of this method, we investigate the relationship between cell area and chloroplast number per cell in compensation-exhibiting lines. Based on our results, we discuss the promotion of chloroplast proliferation in response to the enhanced post-mitotic cell expansion. In addition, we discuss whether the promotion of chloroplast proliferation occurs through an up-regulation of the expression levels of $P D V$ s.

\section{Results and discussion}

\section{Establishment of a method for counting chloroplasts} in situ

We first established a concise method for counting chloroplasts in the subepidermal palisade cells in situ. A reason for focusing on subepidermal tissue is that cellular phenotypes therein are well characterized in compensationexhibiting lines $[10,12,18]$. To count chloroplasts, the first leaves from 21-day-old plants were immersed in $0.05 \%(\mathrm{v} / \mathrm{v})$ Triton X-100 and 1\% (v/v) glycerol under vacuum at room temperature, followed by observation. This method allowed us to clearly observe and count chloroplasts one by one by manually adjusting the focal plane up and down (Figure 1A-E and I). Cells below the subepidermal layer could also be observed (Figure $1 \mathrm{~F}-\mathrm{H}$ ), ascertaining that this method is sufficient to obtain enough depth of focus to analyze the entire subepidermal layer in situ.

\section{Chloroplast number per cell increased in the leaves of compensation-exhibiting lines}

We next investigated the number of chloroplasts per cell in the subepidermal palisade tissue of 21-day-old compensation-exhibiting lines including fugu5, an 3 and KRP2 OE. Chloroplast numbers per cell increased by $30 \%$, $67 \%$ and $141 \%$ in fugu5-1, an3-4 and KRP2 OE lines, respectively, when compared with the WT (Figure 2A). These data were reproducible with small standard 


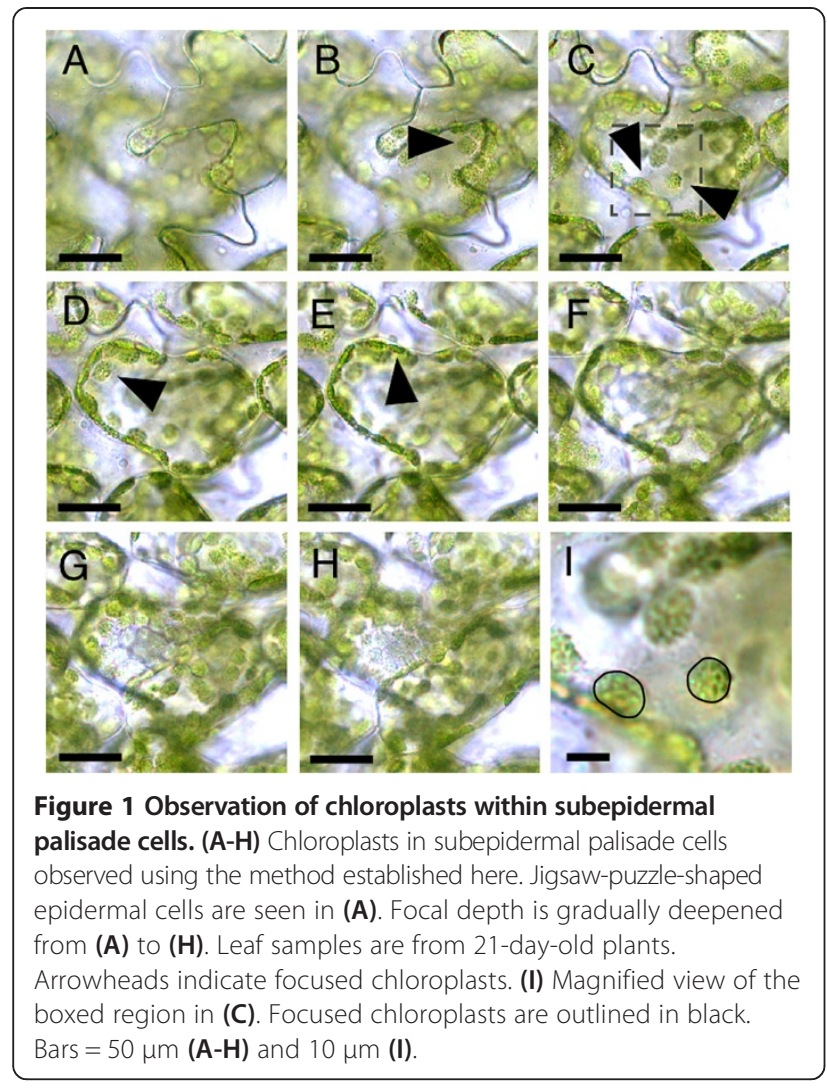

deviations, confirming the validity of our method for counting chloroplast numbers per cell. Furthermore, this result indicates that one of the subcellular processes (i.e., chloroplast proliferation) is modulated in association with the induction of compensation irrespective of the manner by which compensation occurs. In addition, we observed leaf cells from a paradermal view and measured their area using the same leaf samples, which are used also for chloroplast counting. We found that cell area increased by $37 \%, 65 \%$ and $157 \%$ in fugu $5-1$, an3-4 and KRP2 OE, respectively, when compared to the WT (Figure 2A). These increased ratios of cell area are similar to those of the number of chloroplasts per cell: the value of chloroplast number per cell/cell area is constant to a similar extent in compensation-exhibiting lines comparable to the level of WT (although the value is slightly but significantly decreased in KRP2 OE) (Figure 2B). These results suggest a tight relationship between final cell area and chloroplast number per cell in the subepidermal palisade tissue of compensation-exhibiting lines.

Chloroplast proliferation activity decreases with developmental progression in WT leaves [24]. On the other hand, our data indicate that the number of chloroplasts per cell is correlated with final cell area in the mature leaves, which is determined through the postmitotic cell expansion. Mitotic cell area in 5-day-old fugu5-1 and an3-4 lines is similar to that in the WT

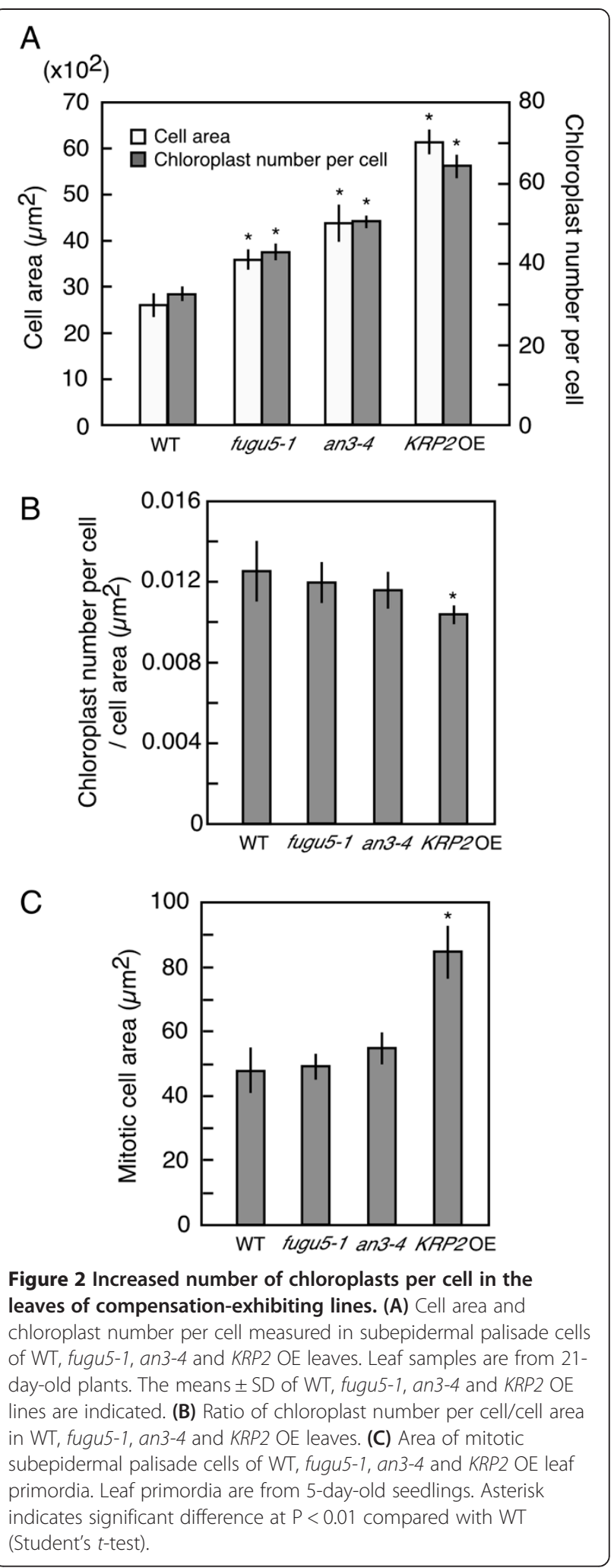

(Figure 2C) [10], supporting our idea that chloroplast proliferation is modulated in response to the status of post-mitotic cell expansion in these mutants. We should 
carefully consider the contribution of post-mitotic cell expansion to promotion of chloroplast proliferation in KRP2 $\mathrm{OE}$, because area of mitotic cells in this line is about two fold larger than that in WT (Figure 2C) [10,13]. Therefore, chloroplast proliferation could be modulated also during mitotic phase of leaf cells. Establishment of method for precise enumeration of immature chloroplasts in mitotic cells would be helpful to further investigate this issue.
Relationship between final cell area, nuclear ploidy and chloroplast number per cell

Final cell area often parallels the level of endoreduplication [32]. In addition, previous studies have shown that AtCDT1a, a component of the prereplication complex for DNA replication, is localized in both the nucleus and chloroplasts, and is involved in the regulation of endoreduplication and chloroplast division [33,34]. These

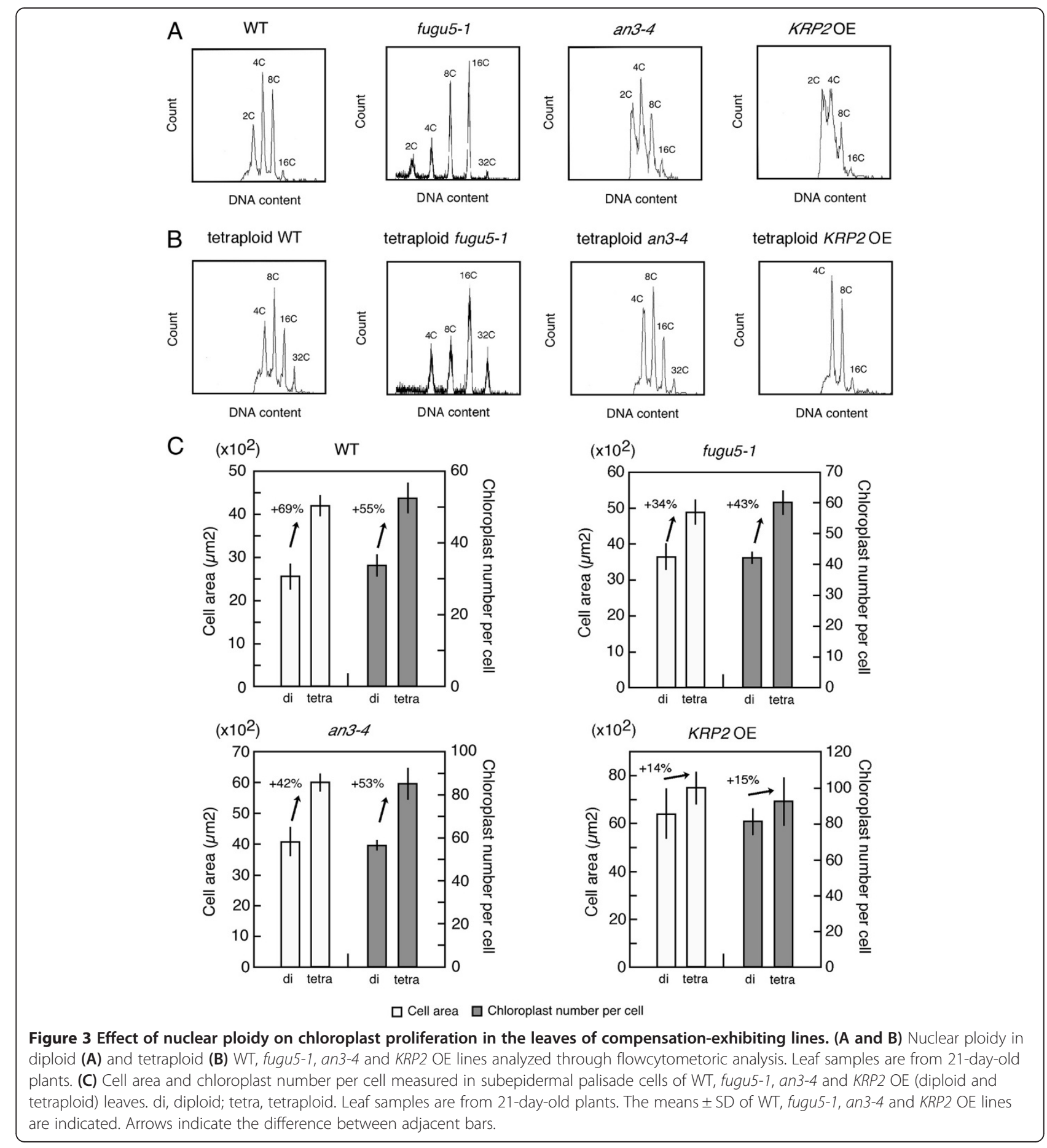


facts suggest that nuclear ploidy is directly linked to chloroplast proliferation through the endoreduplication process. However, we concluded that nuclear ploidy does not directly linked to the chloroplast proliferation in compensation-exhibiting lines because the nuclear ploidy in these lines is varied, namely increased in fugu5-1, relatively normal in an3-4 and decreased in KRP2 OE compared to the WT (Figure 3A) [10,17,35].

Nuclear ploidy is increased through not only endoreduplication but also polyploidization. To further investigate the effect of increased nuclear ploidy on chloroplast proliferation, we established tetraploidized WT, fugu5-1, an3-4 and KRP2 OE lines (Figure 3B) and analyzed their leaves 21 days after sowing. We found that chloroplast number per cell increased by 55\%, 43\%, 53\% and $15 \%$ in tetraploid WT, fugu5-1, an3-4 and KRP2 OE, respectively, when compared with diploid counterparts (Figure 3C). These rates of increase are different from that expected $(100 \%)$ if chloroplast number per cell was linearly correlated with nuclear ploidy. Rather, these rates of increase are similar to those of cell area: in tetraploid WT, fugu5-1, an3-4 and KRP2 OE, cell areas increased by $69 \%, 34 \% 42 \%$ and $14 \%$, respectively, compared to their diploid counterparts (Figure 3C). Together, we conclude that nuclear ploidy does not directly affect chloroplast proliferation, and final cell area is the key parameter for chloroplast proliferation.

\section{Enhanced post-mitotic cell expansion is required for promotion of chloroplast proliferation in an 3}

We previously identified extra-small sister1 (xs1) mutant that shows decreased final cell area in leaves [17]. The $x s 1$ mutation suppresses enhanced post-mitotic cell expansion in an3 genetic background [17], but does not affect cell area in mitotic phase irrespective of WT or an3-4 genetic background (Figure 4A). We next investigate whether promotion of chloroplast proliferation depends on the cell-area increase in post-mitotic phase using xs1 an3-4 double mutant line. The number of chloroplasts per cell decreased in subepidermal palisade tissue of 21-day-old xs1 an3-4 when compared with an3-4 in association with the decrease in final cell area (Figure 4B). We therefore concluded that chloroplast proliferation is promoted in response to the enhanced post-mitotic cell expansion in an3-4.

\section{Chloroplast proliferation is promoted in compensation- exhibiting lines without up-regulation of the expression of PDVs}

It was previously believed that expression level of $P D V s$ determines the rate of chloroplast proliferation because increased or decreased level of $P D V s$ expression lead to an increase or decrease in chloroplast proliferation, respectively [23,24]. The expression for PDVs decreases along

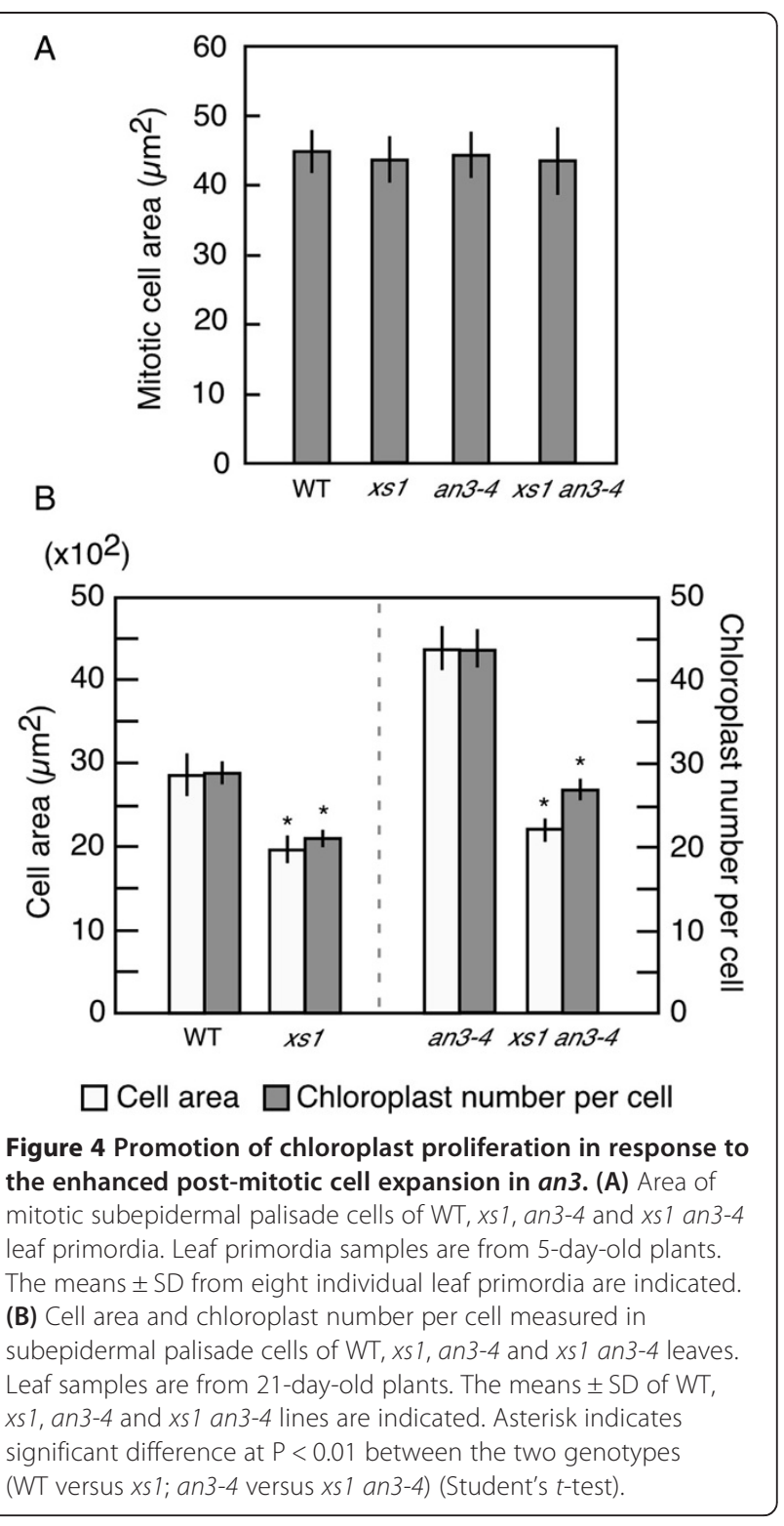

with leaf development in the WT, whereas our data indicate that chloroplast proliferation is promoted in response to increase in cell area. This fact suggests that the control of chloroplast proliferation might be more flexible than previously thought in response to the change in final cell area. If that is the case, whether the expression level of $P D V$ s is up-regulated in response to cell-area change in leaves of compensation-exhibiting lines is an important question.

To address this, we asked whether promotion of chloroplast proliferation occurs through the up-regulation of $P D V$ s expression in compensation-exhibiting lines. We investigated the expression level of $P D V \mathrm{~s}$ in the aboveground parts of 7-day-old seedling and leaf primordia in 14-day-old plants. Increase rate of cell area in fugu5-1, an3-4 and KRP2 OE is already higher than that in WT 
14 days after sowing [10]. However, the expression level of $P D V \mathrm{~s}$ in these compensation-exhibiting lines is similar to or lower than that in the WT (Figure 5A). This result indicates that the promotion of chloroplast proliferation in response to the increase in cell area in compensationexhibiting lines does not depend on the up-regulation of $P D V s$ expression. We further investigated the expression levels of other chloroplast proliferation-related genes in compensation-exhibiting lines, and found that their expression levels are also similar to or lower than that in
WT (Figure 5B). This fact implies that promotion of chloroplast proliferation in compensation-exhibiting lines does not depend on the up-regulation of the expression of chloroplast proliferation-related genes.

\section{Conclusions}

In this study we reported a reliable method for chloroplast enumeration in situ and demonstrated that chloroplast number per cell increases in compensation-exhibiting lines. Nuclear ploidy is not directly involved in the
A

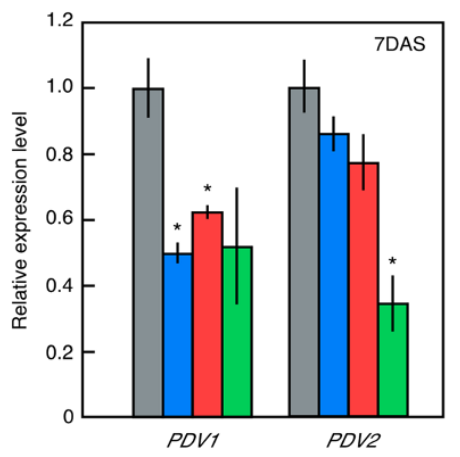

B
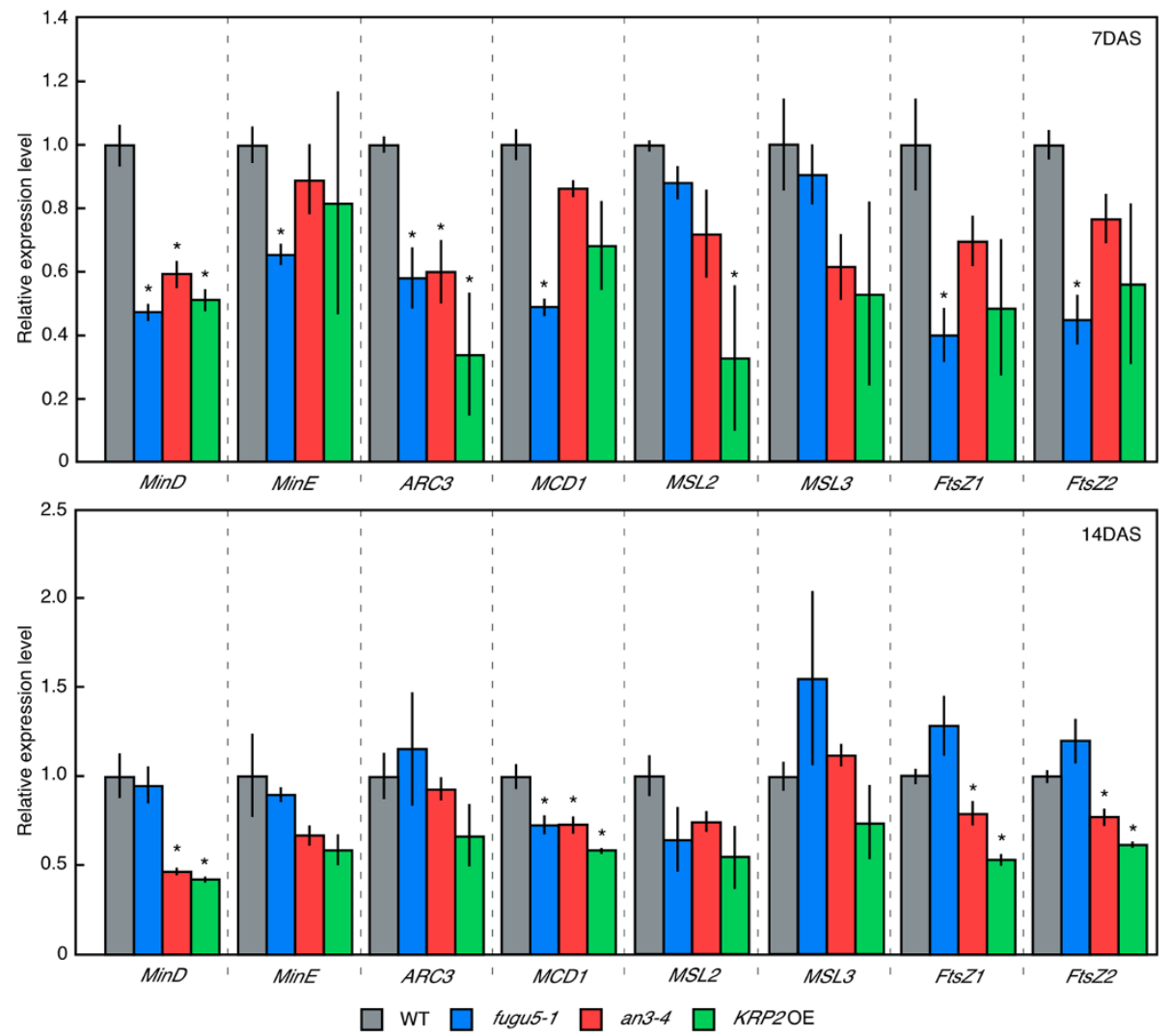

Figure 5 Transcription levels of chloroplast proliferation-related genes in compensation-exhibiting lines. (A and B) Expression levels of PDV1 and PDV2 (A), and other chloroplast proliferation-related genes (B) in WT, fugu5-1, an3-4 and KRP2 OE. Samples are from above-ground parts of 7-day-old seedlings and leaf primordia of 14-day-old seedlings. Transcription levels of chloroplast proliferation-related genes including PDV1 and PDV2 were normalized to that of ACTIN2. Data are means \pm S.D. $(n=3$, with triplicates in each sample). Asterisk indicates significant difference at $P<0.01$ compared with WT (Student's t-test).

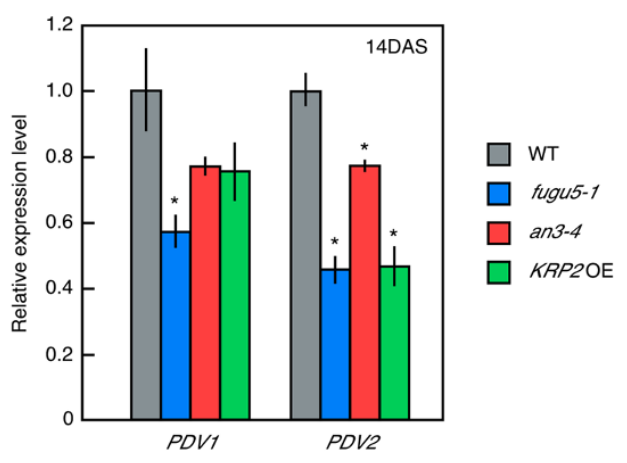


control of chloroplast proliferation in compensationexhibiting lines. Of particular note is the finding that chloroplast proliferation is modulated during leaf development in response to the status of post-mitotic cells. In this process, the expression of $P D V \mathrm{~s}$ and other chloroplast proliferation-related genes were not up-regulated, arguing an as-yet-unknown mechanism for promotion of chloroplast proliferation in response to cell-area change. These findings highlight a novel aspect of compensation, and, therefore, provide important insight into the fundamental understanding of leaf growth.

\section{Methods}

\section{Plant materials and growth conditions}

The WT accession of Arabidopsis used in this study was Columbia-0. Tetraploidization of WT, fugu5-1, an3-4 and KRP2 OE lines were carried out as described previously [36], followed by flowcytometory analysis to confirm their nuclear ploidy [37]. Plants were grown on rock wool at $22^{\circ} \mathrm{C}$ under $16 \mathrm{~h}$ light $/ 8 \mathrm{~h}$ dark, and watered daily with $0.5 \mathrm{~g} \mathrm{~L}^{-1}$ Hyponex solution. Light at approximately $50 \mu \mathrm{mol} \mathrm{m} \mathrm{s}^{-1}$ was provided by white fluorescent lamps.

\section{Chloroplast enumeration}

The first leaves from 21-day-old plants are infiltrated with $0.05 \%(\mathrm{v} / \mathrm{v})$ Triton X-100 and $1 \%(\mathrm{v} / \mathrm{v})$ glycerol, and then counted the number of chloroplasts $(n=160$ cells from 8 leaves for each line). Detailed method is described in the Results and Discussion section.

\section{Measurement of cell area in leaves}

After enumeration of chloroplast number per cell, the same leaf samples are subjected to analyze the cell area ( $n=160$ cells from 8 leaves for each line). Subepidermal palisade cells were observed under a light microscope (DMRX/E; Leica Microsystems). The leaf primordia was fixed in a formalin-acetic acid-alcohol (FAA) and cleared in a chloral hydrate solution (chloral hydrate, 200 g; glycerol $20 \mathrm{~g} ; \mathrm{H}_{2} \mathrm{O}, 50 \mathrm{ml}$ ) to measure the area of mitotic cells in the first leaves dissected from 5-day-old plants.

\section{Quantification of transcripts of chloroplast proliferation- related genes by qRT-PCR}

Total RNA was extracted from above-ground parts of 7-day-old seedlings and primordia of the first leaves in 14-day-old plants using RNeasy Plant mini kit (QIAGEN) according to the manufacturer's instructions. Firststrand cDNA was synthesized from the extracted RNA using ReverTra Ace qPCR RT Master Mix with gDNA remover kit (TOYOBO). The PCR products were monitored by use of StepOnePlus real-time PCR system (Applied Biosystems) using Thunderbird SYBR qPCR mix (TOYOBO). Primers used were as follows: $5^{\prime}$ - CTT
AACGCAATTCGAACCGC - $3^{\prime}$ and $5^{\prime}$ - TCCTGCTCT GTTCAAGCCG - 3' for PDV1, 5' - GCTGAACGGCTT TTGCGTAT - 3' and 5' - AATCAATCTCAGAGAGAG CCAGTTG - 3' for PDV2, and 5' - TCGGTGGTTCCAT TCTTGCT - $3^{\prime}$ and $5^{\prime}$ - GCTTTTTAAGCCTTTGATCT TGAGAG - 3' for ACTIN2, or as described elsewhere [38]. The expression levels of chloroplast proliferationrelated genes were normalized by that of ACTIN2 gene as an internal standard and expressed relative to the WT level $(\mathrm{WT}=1)$. The specificity of PCR amplification was examined by monitoring the melting curves. Data were obtained from three independent biological replicates with triplicates in each sample, and were analyzed statistically.

\section{Authors' contributions}

$\mathrm{KK}$ and $\mathrm{HT}$ designed the research; GH helped design the research; KK performed the main parts of experiments; $\mathrm{GH}$ established xs 1 an3-4 double mutant line; NI and HT carried out tetraploidization of Arabidopsis lines; KK, $\mathrm{GH}, \mathrm{NI}, \mathrm{MYH}$ and $\mathrm{HT}$ wrote the paper. All authors read and approved the final manuscript.

\section{Acknowledgements}

We thank U. Fujikura (Potsdom Univ.) for his advice on the observation of chloroplasts. This work was supported by grants-in-aid for Creative Scientific Research (No. 18GS0313 to H.T.), Scientific Research on Priority Areas (No. 19060002 to H.T.), Scientific Research A (No. 17207005 to H.T. and G.H.), Exploratory Research (No. 18657020 to G.H.), Scientific Research on Innovative Areas (No. 25113002 to H.T. and No. 25113010 to M.Y.H.), a fellowship from the Japan Society for the Promotion of Science (JSPS) (No. 217214 to K.K.), the RIKEN Special Postdoctoral Researchers Program (No. K23253 to K.K.) and the Toray Science Foundation (to H.T.).

\section{Author details}

'Department of Biological Sciences, Graduate School of Science, University of Tokyo, 7-3-1 Hongo, Bunkyo-ku, Tokyo 113-0033, Japan. '2Department of Life Science, College of Science, Rikkyo University, 3-34-1 Nishi-lkebukuro, Toshima-ku, Tokyo 171-8501, Japan. ${ }^{3}$ Research Center for Life Science, Rikkyo University, 3-34-1 Nishi-Ikebukuro, Toshima-ku, Tokyo 171-8501, Japan. ${ }^{4}$ RIKEN Center for Sustainable Resource Science, 1-7-22 Suehiro-cho, Tsurumi-ku, Yokohama, Kanagawa 230-0045, Japan.

Received: 2 September 2013 Accepted: 20 September 2013 Published: 28 September 2013

\section{References}

1. Donnelly PM, Bonetta D, Tsukaya H, Dengler RE, Dengler NG: Cell cycling and cell enlargement in developing leaves of Arabidopsis. Dev Biol 1999 215(2):407-419.

2. Ichihashi Y, Kawade K, Usami T, Horiguchi G, Takahashi T, Tsukaya H: Key proliferative activity in the junction between the leaf blade and leaf petiole of Arabidopsis. Plant Physiol 2011, 157(3):1151-1162.

3. Kazama T, Ichihashi Y, Murata S, Tsukaya H: The mechanism of cell cycle arrest front progression explained by a KLUH/CYP78A5-dependent mobile growth factor in developing leaves of Arabidopsis thaliana. Plant Cell Physiol 2010, 51(6):1046-1054.

4. Andriankaja M, Dhondt S, De Bodt S, Vanhaeren H, Coppens F, De Milde L, Muhlenbock P, Skirycz A, Gonzalez N, Beemster GT, et al: Exit from proliferation during leaf development in Arabidopsis thaliana: a not-sogradual process. Dev Cell 2012, 22(1):64-78.

5. White DW: PEAPOD regulates lamina size and curvature in Arabidopsis Proc Natl Acad Sci U S A 2006, 103(35):13238-13243.

6. Beemster GT, Fiorani F, Inze D: Cell cycle: the key to plant growth control? Trends Plant Sci 2003, 8(4):154-158.

7. Tsukaya $\mathrm{H}$ : Interpretation of mutants in leaf morphology: genetic evidence for a compensatory system in leaf morphogenesis that provides a new link between cell and organismal theories. Int Rev Cytol 2002, 217:1-39. 
8. Tsukaya H: Controlling size in multicellular organs: focus on the leaf. PLOS Biol 2008, 6:1373-1376.

9. Barrôco RM, Peres A, Droual AM, De Veylder L, le Nguyen SL, De Wolf J, Mironov V, Peerbolte R, Beemster GT, Inze D, Broekaert WF, Frankard V: The cyclin-dependent kinase inhibitor Orysa; KRP1 plays an important role in seed development of rice. Plant Physiol 2006, 142(3):1053-1064.

10. Ferjani A, Horiguchi G, Yano S, Tsukaya H: Analysis of leaf development in fugu mutants of Arabidopsis reveals three compensation modes that modulate cell expansion in determinate organs. Plant Physiol 2007, 144(2):988-999.

11. Horiguchi G, Tsukaya H: Organ size regulation in plants: insights from compensation. Front Plant Sci 2011, 2:24.

12. Kawade K, Horiguchi G, Tsukaya H: Non-cell-autonomously coordinated organ size regulation in leaf development. Development 2010, 137(24):4221-4227.

13. De Veylder L, Beeckman T, Beemster GT, Krols L, Terras F, Landrieu I, van der Schueren E, Maes S, Naudts M, Inze D: Functional analysis of cyclindependent kinase inhibitors of Arabidopsis. Plant Cell 2001, 13(7):1653-1668.

14. Kim JH, Kende $\mathrm{H}$ : A transcriptional coactivator, AtGIF1, is involved in regulating leaf growth and morphology in Arabidopsis. Proc Natl Acad Sci U S A 2004, 101(36):13374-13379.

15. Horiguchi G, Kim GT, Tsukaya H: The transcription factor AtGRF5 and the transcription coactivator AN3 regulate cell proliferation in leaf primordia of Arabidopsis thaliana. Plant J 2005, 43(1):68-78.

16. Kawade K, Horiguchi G, Usami T, Hirai MY, Tsukaya H: ANGUSTIFOLIA3 signaling coordinates proliferation between clonally distinct cells in leaves. Curr Biol 2013, 23(9):788-792.

17. Fujikura U, Horiguchi G, Tsukaya H: Dissection of enhanced cell expansion processes in leaves triggered by a defect in cell proliferation, with reference to roles of endoreduplication. Plant Cell Physiol 2007, 48(2):278-286.

18. Fujikura U, Horiguchi G, Ponce MR, Micol JL, Tsukaya H: Coordination of cell proliferation and cell expansion mediated by ribosome-related processes in the leaves of Arabidopsis thaliana. Plant J 2009, 59(3):499-508.

19. Pyke KA, Leech RM: Rapid image analysis screening procedure for identifying chloroplast number mutants in mesophyll cells of Arabidopsis thaliana (L.) Heynh. Plant Physiol 1991, 96(4):1193-1195.

20. Pyke KA, Leech RM: Chloroplast division and expansion is radically altered by nuclear mutations in Arabidopsis thaliana. Plant Physiol 1992, 99(3):1005-1008.

21. Pyke KA, Leech RM: A genetic analysis of chloroplast division and expansion in Arabidopsis thaliana. Plant Physiol 1994, 104(1):201-207.

22. Miyagishima SY, Froehlich JE, Osteryoung KW: PDV1 and PDV2 mediate recruitment of the dynamin-related protein ARC5 to the plastid division site. Plant Cell 2006, 18(10):2517-2530

23. Okazaki K, Kabeya Y, Suzuki K, Mori T, Ichikawa T, Matsui M, Nakanishi H, Miyagishima SY: The PLASTID DIVISION1 and 2 components of the chloroplast division machinery determine the rate of chloroplast division in land plant cell differentiation. Plant Cell 2009, 21(6):1769-1780.

24. Okazaki K, Kabeya Y, Miyagishima SY: The evolution of the regulatory mechanism of chloroplast division. Plant Signal Behav 2010, 5(2):164-167.

25. Osteryoung KW, Stokes KD, Rutherford SM, Percival AL, Lee WY: Chloroplast division in higher plants requires members of two functionally divergent gene families with homology to bacterial ftsZ. Plant Cell 1998, 10(12):1991-2004.

26. Vitha S, Froehlich JE, Koksharova O, Pyke KA, van Erp H, Osteryoung KW: ARC6 is a J-domain plastid division protein and an evolutionary descendant of the cyanobacterial cell division protein Ftn2. Plant Cell 2003, 15(8):1918-1933.

27. Nakanishi H, Suzuki K, Kabeya Y, Miyagishima SY: Plant-specific protein MCD1 determines the site of chloroplast division in concert with bacteria-derived MinD. Curr Biol 2009, 19(2):151-156.

28. Yang Y, Glynn JM, Olson BJSC, Schmitz AJ, Osteryoung KW: Plastid division: across time and space. Curr Opin Plant Biol 2008, 11:577-584.

29. Stokes KD, McAndrew RS, Figueroa R, Vitha S, Osteryoung KW: Chloroplast division and morphology are differentially affected by overexpression of FtsZ1 and FtsZ2 genes in Arabidopsis. Plant Physiol 2000, 124(4):1668-1677.

30. Collettie KS, Tattersall EA, Pyke KA, Froelich JE, Stoke KD, Osteryound KW: A homologue of the bacterial cell division site-determining factor MinD mediates plavement of the chloroplast division apparatus. Curr Biol 2000, 10(9):507-516.
31. Itoh R, Fujiwara M, Nagata N, Yoshida S: A chloroplast protein homologus to the eubacterial topological specificity factor MinE plays a role in chloroplast division. Plant Physiol 2001, 127(4):1644-1655.

32. Melaragno JE, Mehrotra B, Coleman AW: Relationship between endopolyploidy and cell size in epidermal tissue of Arabidopsis. Plant Cell 1993, 5(11):1661-1668.

33. Castellano MM, Boniotti MB, Caro E, Schnittger A, Gutierrez C: DNA replication licensing affects cell proliferation or endoreplication in a cell type-specific manner. Plant Cell 2004, 16(9):2380-2393.

34. Raynaud C, Perennes C, Reuzeau C, Catrice O, Brown S, Bergounioux C: Cell and plastid division are coordinated through the prereplication factor AtCDT1. Proc Natl Acad Sci U S A 2005, 102(23):8216-8221.

35. Verkest A, Manes CLO, Vercruysse S, Maes S, Schueren EVD, Beeckman T, Genschik P, Kuiper M, Inze D, De Veylder L: The Cyclin-dependent kinease inhibitor KRP2 controls the onset of the endoreduplication cycle during Arabidopsis leaf development through inhibition of mitotic CDKA; 1 kinase complexes. Plant Cell 2005, 17(6):1723-1736.

36. Breuer C, Stacey NJ, West CE, Zhao Y, Chory J, Tsukaya H, Azumi Y, Maxwell A, Roberts K, Sugimoto-Shirasu K: BIN4, a novel component of the plant DNA topoisomerase $\mathrm{VI}$ complex, is required for endoreduplication in Arabidopsis. Plant Cell 2007, 19(11):3655-3668.

37. Kozuka T, Horiguchi G, Kim GT, Ohgishi M, Sakai T, Tsukaya H: The different growth responses of the Arabidopsis thaliana leaf blade and the petiole during shade avoidance are regulated by photoreceptors and sugar. Plant Cell Physiol 2005, 46(1):213-223.

38. Nobusawa T, Umeda M: Very-long-chain fatty acids have an essential role in plastid division by controlling Z-ring formation in Arabidopsis thaliana. Genes Cells 2012, 17(8):709-719.

doi:10.1186/1471-2229-13-143

Cite this article as: Kawade et al:: Promotion of chloroplast proliferation upon enhanced post-mitotic cell expansion in leaves. BMC Plant Biology 2013 13:143.

\section{Submit your next manuscript to BioMed Central and take full advantage of:}

- Convenient online submission

- Thorough peer review

- No space constraints or color figure charges

- Immediate publication on acceptance

- Inclusion in PubMed, CAS, Scopus and Google Scholar

- Research which is freely available for redistribution 